\title{
Los Villagómez de Suchitepec, Oaxaca: un cacicazgo mixteco, 1701-1860
}

\author{
John K. Chance \\ School of Human Evolution and Social Change \\ Arizona State University \\ john.chance@asu.edu
}

Recibido: 18 de enero de 2011

Aceptado: 14 de febrero de 2011

\begin{abstract}
RESUMEN
El cacicazgo persistió más tiempo en la Mixteca Baja de Oaxaca occidental y Puebla meridional que en muchas otras partes de Nueva España. Este artículo delinea la historia del segundo cacicazgo en tamaño de la región, el de los Villagómez de Suchitepec, Oaxaca, en los siglos XVIII y XIX. Este estudio de caso ilumina algunas tendencias generales en la Mixteca Baja de la época, incluso el retiro de muchos caciques de los cargos políticos y sus relaciones continuas con sus terrazgueros, a pesar de la oposición creciente en muchos pueblos.
\end{abstract}

Palabras claves: Nobleza indígena, cacicazgo, Mixteca Baja, terrazgueros

The Villagómez of Suchitepec, Oaxaca: A Mixtec Cacicazgo, 1701-1860

\begin{abstract}
The cacicazgo persisted longer in the Mixteca Baja of western Oaxaca and southern Puebla than in many other parts of New Spain. This article sketches the history of the second largest cacicazgo in the region, that of the Villagómez of Suchitepec, Oaxaca in the eighteenth and nineteenth centuries. This case study illuminates some general trends in the Mixteca Baja at the time, including the withdrawal of many caciques from political offices and their continuing relationships with their terrazgueros despite growing opposition in many pueblos.
\end{abstract}

Key words: Indigenous nobility, cacicazgo, Mixteca Baja, terrazgueros

Sumario: 1. Orígenes del cacicazgo Villagómez. 2. Unión de los cacicazgos de Miltepec y Suchitepec y su expansión por herencia. 3. El siglo XIX. 4. Conclusión. 5. Referencias documentales. 6. Referencias bibliográficas.

Los españoles inventaron el término «cacicazgo» para describir los derechos, privilegios, y propiedades de los gobernantes indígenas, o «caciques», en las regiones de América subyugadas por los europeos en el siglo XVI ${ }^{1}$. En Mesoamérica el cacicazgo fue una institución híbrida desde el principio, combinando la práctica indígena con concepciones españolas y un código legal colonial en desarrollo. En el sentido más general, el tenedor de un cacicazgo gozaba derechos de propiedad y derechos señoriales sobre una población subordinada. En la Mesoamérica prehispánica, donde los

\footnotetext{
${ }^{1}$ Mis investigaciones para este trabajo fueron patrocinados por un Fulbright-Hays Faculty Research Grant. Agradezco a John Monaghan su ayuda con aspectos de la genealogía Villagómez y a Patricia Cruz, Justyna Olko y José Luis de Rojas su invitación a participar en este dossier sobre la nobleza indígena de Nueva España.
} 
gobernantes de señoríos o ciudades-estado tenían estrechas conexiones con lo divino, generalmente no se distinguían estas dos clases de derechos. Para la mayoría de los mesoamericanos, y también para los europeos de la época, el dominio político suponía el acceso privilegiado a la tierra y a una población dependiente para trabajarla. En algunas regiones, como la Mixteca Baja de Oaxaca occidental y Puebla meridional, los jefes del estado prehispánicos controlaban por rutina, por lo menos simbólicamente, toda la tierra en sus jurisdicciones (Chance 2009: 106; Menegus Bornemann 2009: 40-47; Terraciano 2001: 140, 320, 340).

Aún en la época colonial tardía, muchos caciques que habían logrado sobrevivir mantenían todavía algunos derechos señoriales sobre su gente. Al mismo tiempo, hay indicaciones de que en la Mixteca Baja y otras partes de Nueva España había un cambio en el manejo del cacicazgo, desde una participación directa en el gobierno local y los asuntos de la comunidad en el siglo XVI, hasta un estilo más impersonal de tenencia de la tierra en la que los arrendatarios españoles podrían tener la misma importancia que los terrazgueros indígenas (Chance 1998, 2003, 2010). Esta transición es evidente en el cacicazgo Villagómez fundado en San Juan Suchitepec, Oaxaca. La historia de esta hacienda, que tenía muchos rasgos en común con los mayorazgos españoles, subraya también otros tres aspectos de los grandes cacicazgos de la Mixteca Baja del siglo XVIII, incluidas (1) las diversas relaciones entre los cacicazgos y los pueblos mixtecos, desde armoniosas hasta altamente antagónicas; (2) la distancia social entre los caciques más afortunados y sus terrazgueros macehuales; y (3) el alto valor de los casamientos estratégicos, incluso mientras los privilegios de los caciques estaban siendo atacados.

\section{Orígenes del cacicazgo Villagómez}

Los dos cacicazgos más grandes en la Mixteca, a finales de la época colonial, estuvieron encabezados por familias con el apellido Villagómez. Estas familias pueden haber compartido una ascendencia común, aunque se les hizo poco caso en el siglo XVIII, cuando ya estaban separadas y diferenciadas. El más grande de los dos cacicazgos Villagómez se fundó en Acatlan y Petlalcingo, con propiedades significativas en Yanhuitlan y Silacayoapan (Chance 2008, 2009). El otro, en el que se centra este trabajo, se concentró en San Juan Suchitepec, aunque sus tierras y terrazgueros se dispersaron por muchas partes de la zona norteña de la Mixteca Baja. Esta hacienda, como veremos, se formó en el siglo XVIII, producto de varios casamientos provechosos entre herederos de diferentes cacicazgos.

Los precursores del gran cacicazgo Villagómez del siglo XVIII se situaron en las comunidades pequeñas y vecinas de Santiago Miltepec y San Juan Bautista Suchitepec, en el corredor al norte de Huajuapan, Oaxaca, hoy la ciudad más grande de la Mixteca Baja. Poco se sabe de la historia prehispánica o colonial temprana de estas comunidades. Caso creyó que Suchitepec, el más grande de los dos, produjo el Mapa de Xochitepec, un manuscrito histórico y genealógico del siglo XVI, probablemente preparado alrededor de 1580 (Caso 1958: 459). Representa un número 
de mojones, descritos en lengua nahuatl. Tambíen hay una serie de 20 gobernantes, los 16 prehispánicos identificados por sus nombres calendáricos mixtecos, y los últimos cuatro por los nombres cristianos de don Alfonso, don Mateo, don Pedro, y don Juan (Caso 1958: 464-465). No he encontrado ningún documento de Suchitepec que confirme que el mapa fue pintado allí. Más significativamente, Smith pensó que su identificación con Suchitepec es poco probable, porque «Xochitepec» aparece en el mapa como conquistado. Dicha autora sugiere que el pueblo principal del documento está representado por una iglesia sin identificar en la sección baja, y que es posible que el mapa se pintara en otro pueblo más al oeste (Smith 1998: 159,195). El mapa perteneció una vez a Mariano Villagómez (1788-1860), el último cacique colonial de Suchitepec (Monaghan 2002: 2), y es probable que se realizara en uno de los pueblos de su cacicazgo.

Aunque la historia colonial temprana de Suchitepec queda poco clara, en 1586, Miltepec, con una población de 70 tributarios, tenía dos caciques, don Domingo de Guzmán, quien fue gobernador a la sazón, y don Felipe de Velasco, el esposo de la hija y heredera designada de don Domingo, doña María de Guzmán. Otro noble, el principal don Juan de San Gabriel, fue nieto del cacique prehispánico Gancho, y aunque el primero pagaba tributo, controlaba un barrio de terrazgueros. En los 1580s, los pueblos de Miltepec y Suchitepec tenían pleito sobre el control de las tierras de Xuliac, donde vivían los terrazgueros de don Juan. La audiencia resolvió el conflicto no adjudicando Xuliac a ninguno de los dos pueblos, sino a don Juan personalmente (aunque el noble subrayó que su lealtad principal fue a Miltepec). Es interesante que, en este pleito, aparentemente sobre los derechos de los pueblos no de los cacicazgos, ninguno de los dos pueblos se quejó de la decisión a favor de un individuo (AGN Tierras 52, exp. 1; Indios 5, exp. 198). Aunque el expediente es enigmático, estos eventos sugieren que el pueblo y el cacicazgo, como entidades legales distintas reconocidas por las autoridades coloniales españolas, no se distinguían todavía con claridad a nivel local en los 1580s. Eso cambiaría marcadamente más tarde, pero por entonces la memoria de los arreglos políticos prehispánicos estaba tan viva que en las mentes de muchos, el cacique, su gente, y sus tierras constituían una unidad singular sobre el modelo del ñuu (señorío) mixteco.

Los archivos se mantienen en silencio para el siglo XVII, y el primer Villagómez conocido en la región fue don Martín de Villagómez y Mendoza, cacique y gobernador de Suchitepec en 1704. No se conocen sus antecedentes, pero su esposa fue una Guzmán, quizás de Miltepec. Uno de sus hijos, don Martín Joseph Villagómez Mendoza y Guzmán, emparentó con el cacicazgo Villagómez de Acatlan y se convirtió en uno de los caciques más conocidos (y discutidos) de la Mixteca de principios del siglo XVIII (Chance 2008, 2009). Otro hijo, don Joseph de Villagómez Guzmán Mendoza, permaneció en Suchitepec y heredó el cacicazgo de su padre, a pesar de que el segundo murió intestado en 1715 (ver Figura 1) (AGN Tierras 2970, exp. 20).

Al mismo tiempo, hay mención del primer Villagómez conocido en Miltepec, el cacique don Lorenzo de Villagómez y Guzmán, quien se casó con doña Paula de Velasco. Un observador contemporáneo dijo que todas las tierras de Miltepec pertenecían al cacicazgo de don Lorenzo, aunque en 1717 el cacique vivía en Huajuapan 


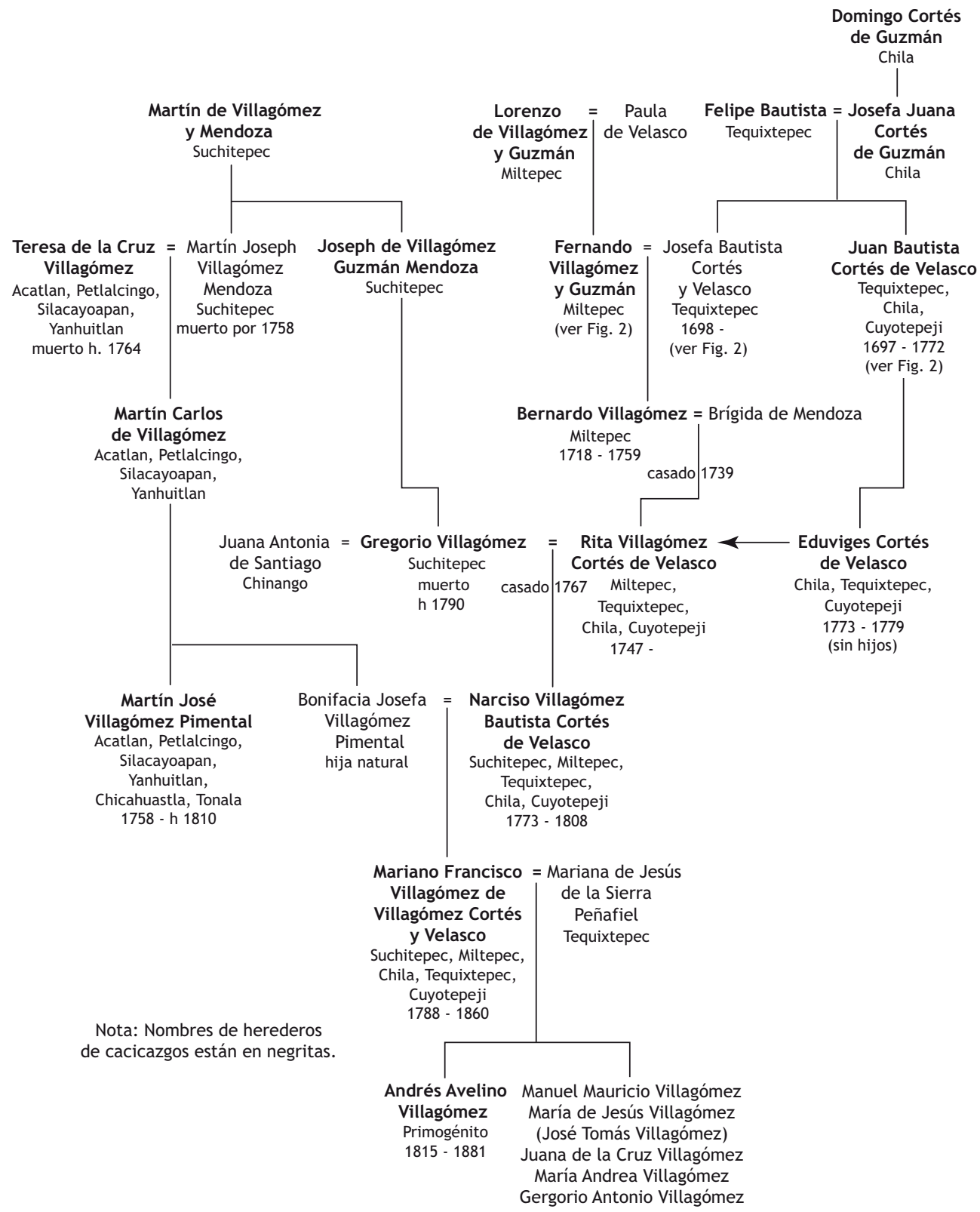

Figura 1: Los caciques Villagómez de Miltepec y Suchitepec. 
donde tenía una tienda (AGN Tierras 1251, exp. 2, fol. 37v; Indios 41, exp. 196; Indios 42, exp. 77; Indios 43, exp. 29). ¿De dónde venían estos Villagómez primeros y cuándo y cómo llegaron a Miltepec y Suchitepec? No hay información, pero sugiero que unos varones Villagómez de la región de Acatlan-Petlalcingo, donde el apellido ya era prominente hacia finales del siglo XVI, se casaron con mujeres locales en Miltepec y Suchitepec en algún momento a finales del siglo XVII ${ }^{2}$. La esposa de don Lorenzo, de apellido Velasco, era tal vez descendiente de don Felipe de Velasco, el cacique de Miltepec en el siglo XVI antes mencionado. Pero en los primeros años del siglo XVIII, los cacicazgos Villagómez de Miltepec y Suchitepec eran entidades separadas. Probablemente estaban conectados por lazos de parentesco, pero todavía no se puede demostrar.

Hacia 1718, el pequeño pueblo de Miltepec sostenía sólo un cacicazgo y el gobernador era el hijo de don Lorenzo, don Fernando de Villagómez y Guzmán. Su preeminencia local no impidió su encarcelamiento por una deuda que su padre debía al alcalde mayor de Huajuapan. Hasta esas fechas, el pueblo y cacicazgo de Miltepec, aunque legalmente distintos según la ley española, no se distinguían para la mayoría de los residentes. Los cargos de cacique y gobernador todavía no se habían diferenciado, como era el caso en muchas otras comunidades mixtecas, y el cacique del pueblo tenía dominio efectivo sobre todas las tierras de la comunidad. Don Fernando reclamó para su cacicazgo un sitio grande de ganado mayor que rentaba a un español por 1.000 pesos el año, una cantidad sustancial. También administraba el arrendamiento de un sitio de ganado menor que el pueblo había recibido por merced en 1617. Aunque don Fernando reconoció que el cacicazgo y el pueblo eran dos entidades distintas que deberían separarse, no se sintió obligado a emprender pasos concretos en esa dirección. En efecto, un siglo después don Fernando fue acusado de usurpar el sitio del pueblo; aparentemente el sitio había quedado en el cacicazgo desde entonces (AGN Indios 41, exp. 196; Indios 42, exp. 77; Indios 43, exp. 29; Tierras 1251, exp. 2, fol. 34v; Tierras 2986, exp. 192, fol. 91v).

Aunque don Fernando no fue el último cacique de Miltepec en servir como gobernador, fue el último en gozar del pleno apoyo y cooperación de la gente del pueblo y su república (cabildo). Pero la enajenación que desarrolló en décadas futuras se debió en parte a las acciones propias de don Fernando. Ya no residió en Miltepec mientras fue gobernador en 1718. Se había casado con una cacica de San Pedro y San Pablo Tequixtepec, doña Josefa Bautista Cortés y Velasco, y la pareja optó por vivir en la comunidad de la esposa. Tequixtepec era más grande y más próspero que Miltepec, y como un pueblo comercial en expansión con un sector pequeño pero creciente de españoles y castas, Tequixtepec también tenía varios caciques y cacicazgos. Uno de ellos perteneció al padre de doña Josefa, don Felipe Bautista. Su madre, doña Josefa Juana Cortés de Guzmán, fue una cacica de Chila, donde tenía propiedades signi-

2 Es posible, pero menos probable, que la familia Villagómez de Suchitepec tuviera raíces en Yanhuitlan en la Mixteca Alta. Un don Rodrigo de Villagómez y Guzmán fue cacique allí en 1674, aunque esta referencia viene después del casamiento de don Diego de Villagómez de Acatlan-Petlalcingo con doña María Pimentel y Guzmán de Yanhuitlan (Romero y Spores, comps. 1976: 109). Agradezco a John Monaghan por llamar mi atención sobre esto. 
ficativas. Desde el punto de vista de don Fernando, su casamiento con una dama más rica y mejor conectada socialmente que él mismo, fue altamente estratégico en términos económicos y sociales, y la decisión de residir en su comunidad de Tequixtepec era un paso lógico. Mientras los padres de doña Josefa escogerían más tarde a su hermano menor como heredero de los cacicazgos de ambos (siguiendo la regla de primogenitura), dos generaciones más tarde y a través de un lance inesperado, esas haciendas llegaron a formar el núcleo de un cacicazgo Villagómez extendido que abarcaba varias comunidades (AGN Tierras 1251, exp. 2, fols. 2-49v).

El hijo de Fernando y Josefa, don Bernardo Villagómez, nació en Tequixtepec en 1718 y murió a la edad de 41 años en 1759 (ver Figura 1). Continuando la tradición familiar, don Bernardo sirvió como gobernador de Miltepec (no se sabe por cuánto tiempo), y poco antes de su muerte se encontró con una ruptura política decisiva entre el pueblo y su cacicazgo. No se sabe hasta qué punto las acciones propias de don Bernardo ayudaron a producir esta escisión, pero el año de 1757 hizo época en la comunidad, cuando recibió las 600 varas de tierra comunal («fundo legal») del gobierno central. En su solicitud, la república se había quejado de la represión por parte de don Bernardo, cuyo cacicazgo controlaba todas las tierras del pueblo. En efecto, toda la tierra del nuevo fundo legal se tomó del cacicazgo; don Bernardo aceptó este arreglo sin quejas, aunque fue gobernador a la sazón (AGN Tierras 1251, exp. 2, fols. 2-49v). Seguramente entendió los cambios en la política agraria en la Mixteca Baja de esa época, pues muchos otros caciques de la región se encontraron en una situación semejante. La ley garantizó los fundos legales a los pueblos, y donde los cacicazgos monopolizaron las tierras de las comunidades, tenían que ceder algunas de sus tenencias sin compensación.

Pero la república de Miltepec no estaba satisfecha con las 600 varas de tierra que recibió, quejándose de que no todo era laborable. Aunque el pueblo tenía sólo 49 casados, muchos menos de los 70 que había a finales del siglo XVI, al año siguiente el pueblo persuadió al alcalde mayor de Huajuapan de que otorgase al pueblo dos parcelas adicionales. Esta vez don Bernardo se opuso, sosteniendo que la concesión violaba sus derechos de cacicazgo. El pleito judicial resultante llegó hasta la audiencia que falló a favor de don Bernardo, pero el cacique murió antes de tomar posesión y el pueblo quedó con el control efectivo de las parcelas (AGN Tierras 1251, exp. 2, fols. 2-49v).

Don Bernardo actuaba en círculos indígenas y españoles y su experiencia en Tequixtepec le dio una perspectiva más cosmopolita, en comparación con los residentes macehuales de Miltepec, la mayoría de los cuales eran campesinos monolingües. Don Bernardo se casó con la cacica doña Brígida de Mendoza, posiblemente de Suchitepec, donde el apellido era bastante común. Don Bernardo probablemente dominaba la lengua castellana, dado que una hermana suya estaba casada con un labrador español, Juan Joseph Rodríguez. El cacique arrendaba unas tierras a su cuñado y a otro español en Teposcolula, Antonio Matías Pérez, con quien tenía intereses mercantiles (AGN Tierras 1251, exp. 2, fols. 2-49v; Tierras 763, exp. 2). 


\section{Unión de los cacicazgos de Miltepec y Suchitepec y expansión por herencia}

La única hija conocida de Bernardo y Brígida fue doña Rita Villagómez Cortés de Velasco, nacida en 1747. Aunque se sabe poco de su vida si sabemos que heredó el cacicazgo pequeño de Miltepec de su padre (su madre, como vimos, no heredó los cacicazgos de sus padres en Tequixtepec y Chila). Doña Rita creció probablemente en Tequixtepec y se casó con otro Villagómez, don Gregorio, de Suchitepec. Don Gregorio era el hijo y heredero de don Joseph de Villagómez Guzmán Mendoza, cacique de Suchitepec, y más probablemente nieto del primer cacique Villagómez de esa comunidad (ver arriba y Figura 1). Don Joseph había sido gobernador en Suchitepec alrededor de 1733, y no fue especialmente acaudalado. Durante más de 12 años, luchó para pagar los rezagos de tributos que debía desde su término de gobernador y por último se vió obligado a hipotecar las tierras de su cacicazgo, su único recurso (AGN Tierras 661, exp. 1, fols. 40v-54v).

Cuando Suchitepec recibió su fundo legal en los 1740s (una década antes que Miltepec), don Joseph se vió atrapado en el fuego cruzado entre los intereses del pueblo y el cacicazgo. Residía con su familia fuera del pueblo, en el Rancho San Joseph, y la república ya no confiaba en su manejo de las finanzas del pueblo, aunque había sido su deber como gobernador. El cacique y otros oficiales del pueblo también estaban «de pique» entre 1744 y 1752 sobre el amojonamiento correcto del fundo legal, lo cual, como en Miltepec, se tomó enteramente de las tierras de cacicazgo. Don Joseph perdió esta batalla, y el cacicazgo Villagómez de Suchitepec se encontraba en una posición débil cuando su hijo don Gregorio se casó con doña Rita Villagómez de Miltepec, en los 1760s (AGN Tierras 1589, exp. 1, fols. 41v-44v) ${ }^{3}$.

Después de la muerte de su padre y una vez tomado el control de su hacienda, una serie de eventos obligó a don Gregorio a dedicar la mayoría de su tiempo a administrar el cacicazgo de su esposa en lugar del suyo. No perdió tiempo en tomar posesión de las tierras que la audiencia había adjudicado al padre de doña Rita, don Bernardo Villagómez, poco antes de su muerte una década antes. Cuando doña Rita recibió la posesión de la tierra formalmente en 1767, la república de Miltepec hizo otra vez objeciones, y el amargo conflicto entre pueblo y cacicazgo continuaba aún después de la muerte de don Gregorio (AGN Tierras 1251, exp. 2, cuaderno 3, fol. 5v). Pero la vida de la pareja cambió enormemente en 1781, cuando doña Rita heredó el cacicazgo grande de su tío abuelo don Juan Bautista Cortés de Velasco, antes cacique de Chila, Tequixtepec, y Cuyotepeji. Este extenso cacicazgo tenía propiedades dispersas en los distritos de Acatlan y Huajuapan, y don Gregorio dedicó el resto de su vida a mantenerlo unido a través de una dilatada litigación con varios pueblos y caciques.

Don Juan Bautista Cortés de Velasco fue quizás el cacique más sagaz en la Mixteca Baja en los primeros años del siglo XVIII. Más despiadado que otros, poseyó tierras en muchos lugares, pero no se sintió en casa en ninguno de ellos. Nacido en Chila en 1697, don Juan heredó allí un cacicazgo de su madre, doña Josefa Juana Cortés y Guzmán, y otro en Tequixtepec de su padre, don Felipe Bautista (ver Figura 2).

\footnotetext{
3 Además de Gregorio, don Joseph tuvo al menos un hijo más, Alberto.
} 


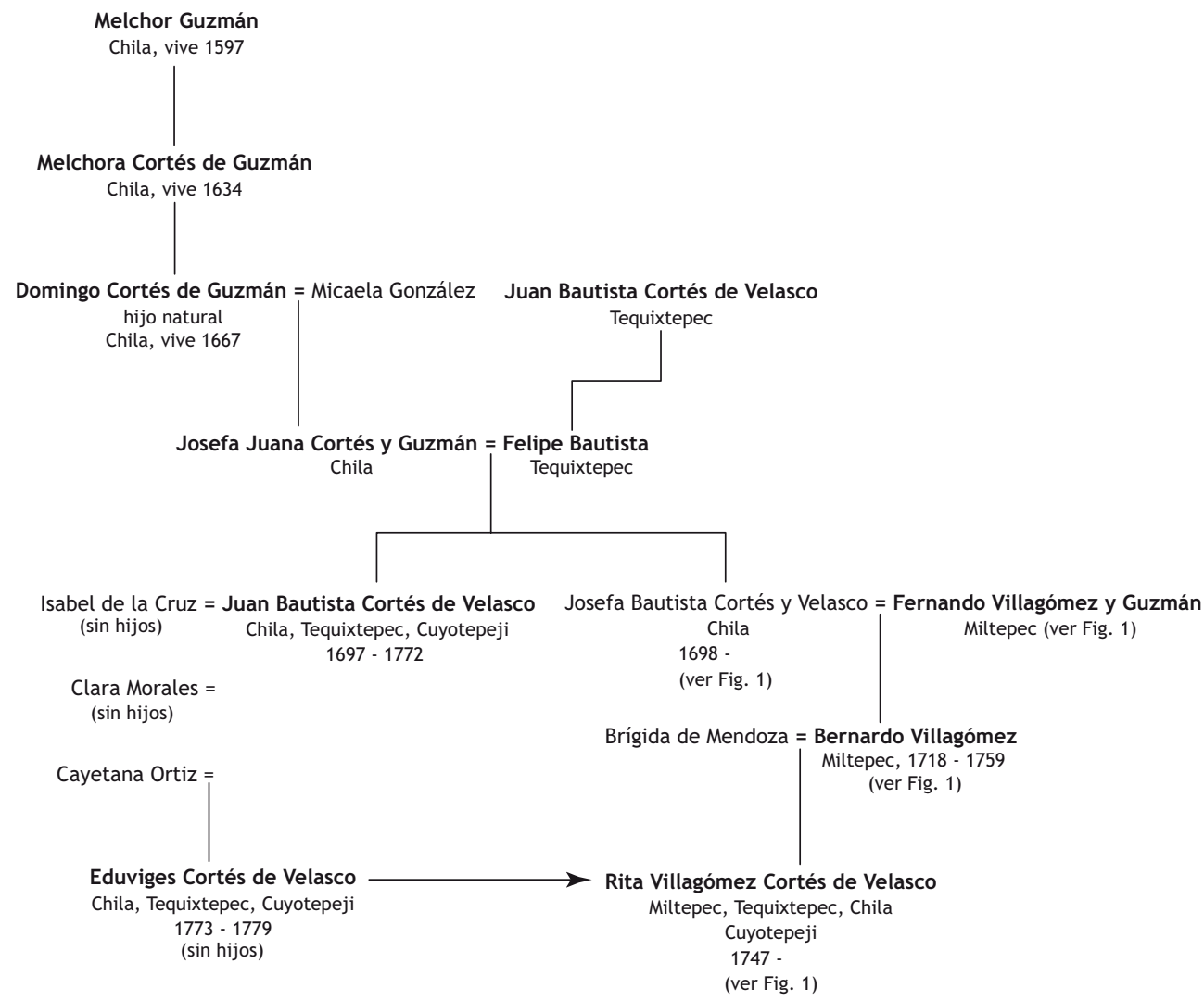

Nota: Nombres de herederos de cacicazgos están en negritas.

Figura 2: Genealogía y herederos del Cacique don Juan Bautista Cortés de Velasco, 1697-1772.

Los antecedentes del padre de don Juan no están claros; se rumoreaba que el abuelo paterno y tocayo de don Juan había inmigrado a Tequixtepec desde el pueblo nahua de Santiago Tecali en el Valle de Puebla (AGN Tierras 1089, exp. 1, fol. 10v). Por contraste, el cacicazgo de Chila se había mantenido sin duda en la familia de la madre de don Juan desde por lo menos finales del siglo XVI, y doña Josefa lo heredó en 1694. Su esposo, don Felipe Bautista, fue gobernador en Chila en 1699 (AGN Tierras 1089, exp. 1, fol. 24-52v) .

\footnotetext{
4 Para detalles sobre los caciques Guzmán de Chila en el siglo XVI, véase AGN Indios 1, exp. 18; Indios 3, exp. 773; y Indios 4, exp. 945. No fue poco común que los caciques sirvieren de gobernador en las comunidades de su esposa. Véase Chance $(2008,2009)$ para más ejemplos.
} 
Cuando ya había alcanzado la edad de 30 años, don Juan dominaba bien la lengua castellana y había adquirido fama como un «hombre rico» y un empresario astuto (AGN Tierras 565, segunda parte, exp. 4). Arrendaba todas sus extensas tierras y las aumentaba por medio de tácticas agresivas y a veces dudosas. Recaudó más de 2.000 mil pesos anualmente de sus arrendatarios españoles en Chila y Tequixtepec, una cantidad superior al promedio entre caciques mixtecos de la época. Sin embargo, dijo al juzgado en 1741, que le faltaba dinero para continuar con los varios pleitos sobre tierras en que estaba involucrado (AGN Indios 55, exp. 3). Durante toda su vida mostró una predilección por la agresión seguida por el remordimiento. En 1732, confesó haber invadido la hacienda de un cura y la restituyó voluntariamente (AGN Tierras 494, exp. 3). En 1770, ya de edad avanzada y temiendo la muerte, don Juan devolvió la tierra que o él o su padre habían usurpado de otro cacicazgo en Chila. Mientras pretendía que hacía esta restitución para limpiar su conciencia, don Juan devolvió tierras a otros dos individuos más o menos en las mismas fechas para evitar un pleito que sabía que probablemente perdería (AGN Tierras 1089, exp. 1, fols. 28, 141).

Aunque fue afortunado en el negocio de bienes raíces, don Juan no participó mucho en la política, al menos no abiertamente. A los 36 años de edad, vivió por un tiempo en Tequixtepec, donde dirigió brevemente una facción en la turbulenta caldera política del pueblo y fue elegido gobernador en 1733. El año siguiente perdió frente a una facción competidora que quedó en el poder durante al menos los siguientes nueve años, y no he podido confirmar que don Juan llegara a desempeñar de nuevo un cargo político (AGN Tierras 525, exp. 1, fol. 84; Indios 54, exp. 5; Indios 55, exps. $169,175$, y 196$)^{5}$.

Hacia 1753, don Juan era conocido en todas partes de la Mixteca por su riqueza y como «dueño de haciendas» (BN Tenencia de la Tierra en Puebla, Caja 2, exp. 195). Se había mudado a la ciudad de Puebla, donde residió el resto de su vida, y dejó sus negocios en la Mixteca en las manos de mayordomos españoles de la región ${ }^{6}$. Pero mientras don Juan maniobraba hábilmente en ambos mundos, mixteco y español, nunca había podido engendrar un heredero (ver Figura 2). Se casó tres veces, y sus dos primeras esposas murieron sin hijos (AGN Tierras 1089, exp. 1, fol. 14v). Más tarde, ya con más de 70 años y mientras residía en Puebla, se casó con su tercera esposa, doña Cayetana Ortiz de Mendoza, hija de un sastre de recursos modestos y descendiente de caciques tlaxcaltecas. Doña Cayetana estaba embarazada cuando don Juan murió en 1772 a la edad de 75 años. Cinco meses más tarde ella dio a luz una hija, doña Eduviges Cortés de Velasco, quien inmediatamente fue declarada heredera del cacicazgo de su padre difunto. Pero la hija murió a la edad de seis años, haciendo saltar un pleito sobre la sucesión que duró dos años. Hubo solicitudes por parte del tío paterno de don Juan, don George (Jorge) Bautista, un cacique de Chazumba; del

5 Documentos en el AGN sugieren que Tequixtepec experimentó dos períodos de turbulencia política cuando rivalidades para cargos políticos locales eran especialmente acaloradas. El primero fue durante el tiempo de don Juan entre 1723 y 1743; el segundo duró desde aproximadamente 1804 hasta los 1850s (AGN Indios 47, exp. 155; Indios 51, exps. 3 y 40; Indios 54, exp. 5; Indios 55, exps. 169, 170, 175, 196; Tierras 525, exp. 1, fol. 84.)

6 Durante 1753-1762, un español de Chila, Isidro Cariño, manejaba los cacicazgos de don Juan (AGN Tierras 1089, exp. 1, fol. 13v). 
padre de doña Cayetana; y de don Gregorio Villagómez en nombre de su esposa, doña Rita Villagómez. Después de considerar todos los argumentos, en 1781, la Audiencia otorgó el cacicazgo entero de don Juan a doña Rita (ver Figuras 1 y 2) (AGN Tierras 1110, exp. 10; Tierras 1089, exp. 1; Tierras 565, segunda parte, exp. 4; Tierras 1452, exp. 3). Esa herencia fue un golpe de suerte para la familia Villagómez, y junto con la unificación por casamiento de los cacicazgos de Miltepec y Suchitepec, consolidó su dominio económico en la Mixteca Baja, superado solamente por la otra familia Villagómez de Acatlan-Petlalcingo (Chance 2008, 2009).

Junto con esta fruta caída llegaron también muchos enredos legales que continuaron durante tres generaciones. Todavía a principios del siglo XVIII, cuando los padres de don Juan poseían sus respectivos cacicazgos en Tequixtepec y Chila, hubo reconvenciones pendientes en ambos pueblos y también en Cuyotepeji y cuatro pueblos más pequeños (AGN Tierras 1097, exp. 61, fol. 27). La familia Villagómez heredó estos problemas y sufrió también muchos nuevos conflictos. La contención exitosa de todos estos conflictos requería tácticas agresivas, y don Gregorio Villagómez respondió adecuadamente. En un pleito con los Villagómez en 1783, un cacique de Acaquizapa, don Esteban Jiménez, caracterizó a don Gregorio como «un notorio ladrón». Don Gregorio defendió el cacicazgo de su esposa comparándolo con los mayorazgos de Castilla, y endosó la sucesión al primer hijo nacido, hombre o mujer, y dijo que era lo que había sucedido en el caso de su esposa doña Rita (AGN Tierras 1097, exp. 6; Tierras 1089, exp. 1, fols. 52r-v) 7 .

El recién aumentado cacicazgo de Villagómez sufrió un revés en Chila, en 1786, cuando el alcalde mayor de Acatlan otorgó las tierras en litigio de El Molino al cacique Isidro Martínez (AGN Tierras 1089, exp. 1, fols. 191, 260). Don Gregorio perdió también otro pleito con el pueblo de Yxitlan (AGN Tierras 1221, exp. 3). Las fortunas de los Villagómez tuvieron más suerte en Tequixtepec, que en vida de de Rita y Gregorio estaba menos dividido que antes (ver nota 5). En la década de los 1770s Tequixtepec, había llegado a ser una comunidad grande para la Mixteca Baja cosmopolita. Gregorio y Rita residieron allí con sus tres hijos, Narciso, Mariana, y Antonia, junto con el tío paterno de Gregorio, don Alberto Villagómez, y su familia. Tequixtepec tenía entonces otras 22 familias de caciques y 46 familias de gente de razón, incluso 28 de españoles y 33 de castas. En conjunto, de la población de 800 personas, 62 por ciento eran indios macehuales, 23 por ciento españoles o castas, y 14 por ciento caciques de varios pueblos de la región (AGI Audiencia de México 2581) 8 . Don Gregorio tomó posesión de las tierras de cacicazgo de su esposa en 1783; ambos eran reconocidos como caciques y hasta sus respectivas muertes se sostuvieron en parte por los terrazgueros que había en sus tierras.

7 Este principio de sucesión difiere de la ideal tradicional español de la época, sucesión por el primer hijo varón, o primogenitura.

8 En comparación, Miltepec en 1777 tenía solo 34 familias indígenas y un español (probablemente un maestro de escuela), y Suchitepec tenía 70 familias, todas indígenas. Curiosamente, según estos padrones parroquiales, ninguna de los residentes de estos dos pueblos llevaba el apellido Villagómez (AGI Audiencia de México 2581). 
El cacicazgo Villagómez no fue el único en Tequixtepec, pero parece que fue el principal. Según don Gregorio, abarcó el centro residencial del pueblo antes de la medida del fundo legal en 1762 (AHJO Huajuapan Civil, Legajo 3, exp. 3, fols. 7-91). Siguiendo los pasos de don Juan Bautista, don Gregorio, poco antes de su muerte alrededor de 1790, devolvió unas tierras al pueblo, que dijo que tenía injustamente (AHJO Huajuapan Civil, Legajo 2, exp. 1, fols. 1-3) ${ }^{9}$. No hay indicación de que don Gregorio ocupara cargos políticos en Tequixtepec u otra parte, y esta falta de compromiso político formal continuó entre sus sucesores. Los últimos caciques conocidos que sirvieron de gobernador en lo que llegó a ser el cacicazgo Villagómez fueron don Juan Bautista Cortés de Velasco en Tequixtepec en 1733, don Joseph de Villagómez en Suchitepec en los 1730s y 1740s, y don Bernardo Villagómez en Miltepec en 1757. En todos los tres casos, y en muchos otros en la Mixteca, existieron grandes desacuerdos entre las repúblicas, que representaban los intereses de los macehuales (o de una facción de macehuales), y los caciques, quienes se retiraron de la política de las repúblicas por preferencia o por fuerza. En todos los casos, la cuestión principal fue el acceso a la tierra.

Don Gregorio murió alrededor de 1790 (doña Rita ya había fallecido antes), y su hijo mayor, don Narciso Villagómez Bautista Cortés de Velasco, tomó el control de los cacicazgos combinados de su padre y madre a la tierna edad de 17 años. Don Narciso nació y creció en Tequixtepec, pero su matrimonio y problemas de salud le arrancaron de los pueblos de su cacicazgo y murió de tifus a la edad de 35. Su casamiento, sin embargo, continuó la tradición familiar de matrimonios estratégicos, y si hubiera estado mejor de salud y vivido más años, hubiera recogido más beneficios. Su novia, doña Bonifacia Josefa de Villagómez Pimentel, era de Petlalcingo. El hermano de ella, don Martín José Villagómez Pimentel, era heredero del cacicazgo grande de Acatlan-Petlalcingo (ver Figura 1). El casamiento de don Narciso fortaleció los lazos entre los dos cacicazgos más grandes de la Mixteca Baja, que se habían vinculado ya una vez antes cuando el abuelo paterno de doña Bonifacia, don Martín Joseph Villagómez de Suchitepec, se casó con la heredera doña Teresa de la Cruz Villagómez de Acatlan (AGN Tierras 1452, exp. 3, fol. 16). Como hemos visto, las alianzas matrimoniales eran un aspecto clave del éxito de los Villagómez de Suchitepec. Este fue un medio principal de supervivencia entre familias de caciques en la Mixteca (y otras partes de Mesoamérica), al menos desde la época Postclásica. Pero los Villagómez de Suchitepec usaron este medio con más éxito que muchos de sus homólogos. Faltando una base firme en el Postclásico o el siglo XVI en los pueblos de su cacicazgo, el ascenso de los Villagómez, desde circunstancias modestas a la riqueza en el siglo XVIII, se apoyaba fuertemente en lazos matrimoniales con vecinos más ricos y poderosos. Otras familias de caciques, incluso los Villagómez de Acatlan-Petlalcingo, tropezaron más a menudo en sus alianzas matrimoniales y pagaron un precio (Chance 2008, 2009).

Como sus padres, don Narciso vivía en gran parte de las rentas de sus propiedades. Sólo en la jurisdicción de Huajuapan arrendaba pastos a siete españoles (incluso un

9 Don Gregorio hizo esta confesión en la presencia de su segunda mujer, doña Juana Antonia de Santiago, una cacica de Santa Catarina Chinango, con quien se había casado un año antes. 
cura y el subdelegado) y otras tierras a los pueblos de Suchitepec y Patlanala (AGN Tierras 1452, exp. 3, fols. 1-22). No tenía lugar fijo de residencia, pasando unos años en Petlalcingo, el pueblo de su esposa, por lo menos dos períodos en Puebla, probablemente en busca de atención médica y, finalmente, varios años en Huajuapan, donde falleció (AHJO Huajuapan Civil, Legajo 2, exp. 1, fol. 106). También se puede atribuir su ausencia de su cacicazgo a la creciente oposición en los pueblos. La cantidad de litigios aumentó de acuerdo con esto y don Narciso tenía muchas deudas para poder pagar las costas. En Chila continuaba el conflicto con el cacicazgo Martínez, que databa del tiempo de don Gregorio, y don Narciso perdió sus tierras en El Molino por una decisión de la audiencia en 1792 (AGN Tierras 1089, exp. 1, fol. 260). Sus fortunas eran tan precarias que seis años más tarde fue encarcelado por no pagar los derechos del juzgado y otros 2.000 pesos en rentas que debía al cacique Isidro Martínez (AGN Tierras 1452, exp. 3, fols. 1-22).

Pero los mayores dolores de cabeza de don Narciso estaban en Tequixtepec, donde el cacicazgo Villagómez controlaba 27 caballerías de tierra trabajada por terrazgueros. A principios del siglo XIX, Tequixtepec fue uno de los pueblos más litigiosos de la Mixteca, manteniendo pleitos simultáneos con tres pueblos vecinos y seis caciques diferentes, incluido don Narciso. Él y el pueblo nunca pudieron ponerse de acuerdo sobre la medida del fundo legal. Don Narciso sostenía, como su padre anteriormente, que como el pueblo estaba fundado dentro de su cacicazgo, sus habitantes tenían que pagarle renta. La audiencia falló a favor de don Narciso un año antes de su muerte pero Tequixtepec, característicamente, se negó a obedecer la sentencia. Las relaciones entre don Narciso y sus terrazgueros se agriaron; continuaban cultivando sus tierras, pero se negaron a pagarle la renta acostumbrada de 30 pesos al año por sus propios terrenos hasta que se vieron obligados a firmar un contrato formal. Don Narciso echó la culpa de sus problemas en Tequixtepec al subdlegado de Huajuapan, diciendo que el oficial favoreció al pueblo a su costa. El conflicto quedó pendiente a la muerte de don Narciso en 1808 (a pesar de la adjudicación a su favor el año anterior), su hacienda insolvente, y sus tierras pesadamente hipotecadas. Las fortunas del cacicazgo Villagómez habían llegado a un punto muy bajo (AHJO Huajuapan Civil, Legajo 2, exp. 1, fol. 192v; Legajo 3, exp. 3, fols. 7v, 11, 20v-97).

\section{El siglo XIX}

Acosado por campesinos mixtecos hostiles y oficiales españoles, muchas veces inclementes, el futuro del cacicazgo seguía siendo dudoso al principio de las guerras de Independencia en 1810. Pero se recuperó notablemente bajo la administración agresiva del hijo y heredero de don Narciso, don Mariano Francisco Villagómez de Villagómez Cortés de Velasco. Don Mariano era todavía menor de edad cuando heredó el cacicazgo, pero desde aproximadamente 1817 hasta su muerte en 1860 , defendió infatigablemente las propiedades de la familia ante fuerzas abrumadoras. Heredando una hacienda pesadamente hipotecada, don Mariano se enfrentó con un contingente de campesinos cada vez más provocativo, animado por la insurrección 
de Morelos que se extendía por el paisaje oaxaqueño. Un realista hasta el fin (como la mayoría de caciques), don Mariano se esforzó por adaptarse a la abolición de las leyes de vinculación que quitó la base legal de los mayorazgos y cacicazgos por igual. La Independencia mexicana en 1821 puso fin también al reconocimiento legal de la nobleza indígena, y don Mariano fue conocido en la región durante la mayor parte de su vida como un «ex-cacique». También fue el primero de su familia en casarse con una española criolla, doña Mariana de Jesús de la Sierra Peñafiel, una mujer con antecedentes en Tequixtepec, aunque su familia se había mudado a Suchitepec antes de su matrimonio (AHJO Huajuapan Civil, Legajo 5, exp. 2; Monaghan 2005: 421). La hacienda Villagómez había decaído bajo el padre de don Mariano, quien, como su propio padre anteriormente, se identificó con Suchitepec pero no vivía allí. Don Mariano, por el contrario, construyó su casa en tierras de su cacicazgo en el Rancho del Castillo en la municipalidad de Suchitepec. Esto le proporcionó una presencia local, aunque su residencia fuera del centro del pueblo también simbolizaba la creciente distancia social y cultural entre los vecinos y la familia Villagómez de ex-caciques.

Los únicos pueblos mayores del cacicazgo donde don Mariano no se enfrentó con litigios fueron Suchitepec y Chila. En Chila, mientras su padre había perdido las tierras en El Molino (ver arriba), el cacicazgo poseía todavía tierras en el pueblo sujeto de San José Chapultepec que pagaba rentas a don Mariano de 40 pesos por año (AGNP Acatlan, Protocolo de 1819, núm. 2). El primer reto a don Mariano fue en Cuyotepeji, en 1812, cuando el pueblo, bajo la bandera de las fuerzas de Morelos, invadió tierras de Villagómez en el Rancho de Cabras y la Cañada de Solano, reclamando que el padre de don Mariano las había usurpado. Aunque don Mariano se sintió sin fuerzas a la sazón, los vientos políticos cambiaron cinco años después, y cuando presentó su demanda para restitución en 1817, el pueblo la concedió sin pelea y aún dijo que le reconoció como su cacique (AHJO Huajuapan Civil, Legajo 3, exp. 15).

Conforme declinaba el pleito con Cuyotepeji (por ahora), estalló otro en Miltepec, donde don Mariano puso una demanda en 1817 para recuperar una extensión grande de tierra que el pueblo había invadido. El cacique se sintió acosado por dos lados. Vio como su enemigo, el subdelegado de Huajuapan, quería destruir el cacicazgo Villagómez. Don Mariano defendió sus intereses al sostener que el cacicazgo debería tratarse exactamente como los mayorazgos, con sus derechos de vinculación (los cuales todavía estarían en efecto durante otros cuatro años). Como respuesta, el subdelegado calificó a don Mariano de «ladrón» que usurpaba tierra de pueblos indígenas con mala fe, aunque sabía que el cacique tenía el apoyo de algunos clérigos de la región. Por otra parte, don Mariano se sintió igualmente enajenado por los vecinos mixtecos de Miltepec. Desde su rancho en El Castillo menospreciaba el carácter de los indios en general, quienes a su parecer sólo querían agarrar sus tierras de cualquier manera posible. Un año más tade la audiencia devolvió las tierras en Miltepec a don Mariano; el pueblo apeló la decisión pero faltaba la documentación para una argumentación convincente. Sin embargo, hacia 1820, los vecinos invadían de nuevo las tierras en conflicto (AGN Tierras 2986, exp. 192; Tierras 1251, exp. 2, fols. 6-23; Tierras 1418, exp. 6 , fols. $56,126,137,175 \mathrm{v})$. 
Al mismo tiempo que demandaba a Cuyotepeji y a Miltepec, don Mariano también perseguía los intereses del cacicazgo en el litigioso pueblo de Tequixtepec. Poseyendo solamente las tierras de su fundo legal, y con una población que se había doblado en los últimos 50 años (rebasando 1000 habitantes en 1824), Tequixtepec buscaba desesperadamente espacio para crecer y había declarado la guerra a varios cacicazgos que en conjunto controlaban 440 caballerías de tierra en los alrededores del pueblo. El padre de don Mariano, don Narciso, había ganado su pleito con Tequixtepec sobre 27 caballerías en 1807, pero como de costumbre durante este período, los fallos de los juzgados parecían poco más que comentarios sobre las tensiones agrarias en la Mixteca Baja. Pueblos como Tequixtepec, que necesitaba tierra con urgencia, simplemente ignoraban las decisiones judiciales. En 1811, en su juventud, don Mariano se unió a otro cacique para hacer una demanda contra la república de Tequixtepec por falsificación de documentos. Hacia 1819, el gobernador del pueblo firmó un convenio con don Mariano acerca de las tierras de su cacicazgo, pero luego faltó a su palabra, moviendo al frustrado subdelegado de Huajuapan a quejarse de que Tequixtepec se había negado a reconocer la autoridad de su juzgado. Veinticinco años más tarde, don Mariano ganó otro pleito contra Tequixtepec tomó posesión de las tierras en 1845, pero el pueblo apeló la decisión (AHJO Huajuapan Civil, Legajo 2, exp. 1; Legajo 3, exp. 10; Legajo 4, exps. 6 y 20; Legajo 5, exp. 2; Legajo 12, exps. 6 y 19).

Hacia los 1840s, la independencia mexicana estaba en su tercera década y el excacique don Mariano, «el último poseedor del cacicazgo de Suchitepec» según uno de sus abogados, se adaptó a las nuevas restricciones sobre la vinculación al poner partes de sus tierras a nombre de otras personas, probablemente parientes, pero sin abandonar su control (AHJO Huajuapan Civil, Legajo 13, exp. 2). De unos 50 años de edad y acercándose a la última década de su vida, don Mariano, lejos de sentirse desalentado por la hostilidad continua de los pueblos de su «ex-cacicazgo», encontró nuevas reservas de energía para insistir en sus demandas. Los dos ruedos principales de conflicto quedaron en Tequixtepec y Cuyotepeji. Dentro de los límites de la república de Tequixtepec se contradecían todas las reclamaciones de los cacicazgos, aunque los Villagómez ganaron un pleito adicional en 1856. A pesar de los mayores esfuerzos de don Mariano, estos asuntos nunca se resolvieron. Como señala Monaghan, arrendatarios indígenas de los ex-caciques, descendientes de los terrazgueros coloniales, adoptaron una interpretación radical de las Leyes de Reforma de los 1850s y pintaron a caciques como don Mariano «como señores feudales que se deberían eliminar con los otros restos del régimen antiguo» (Monaghan 2005: 420). En un momento triste, don Mariano observó que los fallos judiciales parecían sin sentido y que los indios no respetaban «los derechos sagrados de la propiedad privada garantizadas por la Constitución» (AHJO Huajuapan Civil, Legajo 21, exp. 5; Legajo 23, exps. 8, 9, y 16; Legajo 31, exp. 3).

En Cuyotepeji, el pueblo había ganado una demanda contra don Mariano, sosteniendo que él les había cobrado renta durante 31 años por el uso de tierra que don Juan Bautista Cortés de Velasco había donado al pueblo un siglo antes (AHJO Huajuapan Civil, Legajo 17, exp. 3). Los vecinos le llamaron «señor feudal», un epíteto que no consideraban exagerado ya que el centro del pueblo y aparentemente 
toda la tierra cultivada todavía formaban parte del cacicazgo, y los residentes habían estado pagando renta hasta por sus solares. Un episodio de 1850 y 1851 representa gráficamente la naturaleza híbrida del ex-cacicazgo Villagómez 30 años después de la Independencia. Una decisión judicial en 1850 confirmó el derecho de don Mariano a cobrar a Cuyotepeji 180 pesos anualmente por el uso de sus solares y tierras cultivables, y el pueblo consintió en pagar. No queriendo confiar en los entendimientos tradicionales no escritos, don Mariano pidió y recibió las firmas de los oficiales de Cuyotepeji en un contrato formal de arrendamiento por cinco años. El contrato tenía 37 páginas con 24 cláusulas distintas para anticipar todas las contingencias posibles, pero el pueblo cesó sus pagos después de tres años cuando hubo una epidemia de cólera. Siguió un feo escenario cuando el juez de Huajuapan apoyó el derecho de cobrar de don Mariano y mandó secuestrar los animales de los vecinos de Cuyotepeji con la asistencia de tres soldados armados.

Este evento y otros parecidos en la Mixteca entre 1750 y 1850 , parecen indicar que la estructura interna de derechos y obligaciones entre caciques y terrazgueros, tan importantes durante la colonia, había fracasado y había sido sustituída por arreglos contractuales más impersonales promovidos por el gobierno mexicano y su nuevo sistema judicial. Pero hay más aspectos de esta historia. Al mismo tiempo que don Mariano redactaba el contrato de arrendamiento para las firmas de los miembros de la república, también recibía señales tradicionales de respeto de sus inquilinos en el pueblo, incluyendo regalos de tortillas, comidas, pollos, y guajolotes para fiestas familiares. Estas señales de respeto seguían, aún cuando la república resistió y contravino los fallos judiciales. El hijo y heredero principal de don Mariano, Andrés Villagómez, seguía recibiendo regalos de comida como reconocimiento de sus derechos señoriales después de la muerte de su padre en 1860 (AHJO Huajuapan Civil, Legajo 12, exp. 7; Legajo 18, exp. 2; Legajo 21, exp. 5). Esta amalgama híbrida de costumbres tradicionales y «modernas» no era insólita en la Mixteca Baja, donde los campesinos habían dependido por mucho tiempo de los caciques para el acceso a la tierra. Hasta que las leyes se cambiaron después de la Independencia, esta amalgama se sostenía también por la estipulación legal de que los dueños de cacicazgo tenían que ser indios de ascendencia noble. Mientras este requisito era muchas veces poco más que una ficción legal a finales del siglo XVIII, caciques de la época de ascendencia mixta sabían bien que sus enemigos podían acusarles en el juzgado si no tenían cuidado. Por eso, mientras permaneció el marco colonial, los caciques encontraron buenas razones para mantener las costumbres indígenas locales, si bien buscaban también reducir la tensión con repúblicas hostiles con procedimientos más contraactuales. El aspecto notable del cacicazgo Villagómez en Cuyotepeji era que esta institución híbrida, forjada en tiempos coloniales, persistía más de 40 años después de la Independencia ante un régimen legal nuevo que pretendió eliminarla.

Cuando murió en 1860, don Mariano dejó una hacienda valorada entre 30.000 y 40.000 pesos (AHJO Huajuapan Civil, Legajo 30, exps. 17 y 26). Este ex-cacicazgo fue el segundo en tamaño en la Mixteca Baja, pero se valoró en menos de un tercio del cacicazgo más grande, el de los Villagómez de Acatlan-Petlalcingo, valorado en 130.000 pesos en 1821 antes de su división (Chance 2008: 84; 2009: 
113). Don Mariano había pagado las hipotecas firmadas por su padre e hizo un negocio provechoso, aunque se puede cuestionar cuán provechoso. Ademas de las tierras principales en Suchitepec, Miltepec, Cuyotepeji, Tequixtepec, y Chila, también había cuatro ranchos y otras propiedades más pequeñas en los pueblos de Cuautepec, Misquistlahuaca, Tlacotepec, San José Chapultepec, Acaquizapa, Zapotitlán Palmas, Chilistlahuaca, y, antes de que se vendieron al pueblo, en Patlanala, en el distrito de Silacayoapan (AHJO Huajuapan Civil, Legajo 30, exps. 17 y 26; Legajo 34, exp. 4). Viudo en 1856, don Mariano pasó sus últimos años yendo y viniendo entre su rancho en Suchitepec y Huajuapan, donde tenía dos casas. Una de sus hermanas se había casado con un comerciante de Huajuapan, y don Mariano tenía tratos mercantiles con varios criollos. Poseía otras casas en Petlalcingo, Tequixtepec, Suchitepec (centro), y en el Rancho de las Cidras. Como sus antecesores, derivaba su ingreso de una mezcla de rentas y comercio, aunque no se sabe la cantidad del segundo. Este ex-cacique, como otros de su tiempo, tenía poco interés en trabajar sus tierras él mismo. En una región dedicada principalmente al pastoreo de ganado mayor y menor, don Mariano poseyó personalmente en 1860 sólo 33 caballos, 30 vacas, cuatro bueyes, y dos mulos (AHJO Huajuapan Civil, Legajo 34, exp. 4).

La mayoría de los otros ex-caciques que quedaban en la Mixteca Baja a mediados del siglo XIX sin duda envidiaban el éxito de don Mariano como terrateniente y pequeño empresario. Pero lo logró con un gran costo. Don Mariano pasaba gran parte de su vida en los juzgados manteniendo la unidad de su hacienda, y hacia 1850 estaba gastando entre 500 y 600 pesos anualmente en la litigación. Siempre un litigante tenaz, en sus últimos años se cansaba de los constantes conflictos que disminuían su satisfacción en lo que había logrado (AHJO Huajuapan Civil, Legajo 18, exps. 2 y 3). Y se puede cuestionar exactamente qué había logrado. Aunque restableció la solvencia del cacicazgo casi insolvente que heredó de su padre, los propios hijos de don Mariano consideraban los grandes gastos de litigación como la razón principal de un descenso en el valor de la hacienda durante su vida (Monaghan 2005: 420). Sea cual sea el balance, la tenacidad de don Mariano en defender sus propiedades en un ambiente social y legal cada vez más hostil a la vinculación y los privilegios nobles, fue impresionante.

Monaghan y otros han descrito hábilmente la situación del cacicazgo Villagómez a finales del siglo XIX, después de la muerte de don Mariano. Siguiendo la regla de la primogenitura, Andrés Avelino Villagómez, el mayor de sus nueve hijos, fue el heredero principal, y la familia acordó que él sería el último en poseer el vínculo (Monaghan et al. 2003: 133). Andrés resultó ser un administrador capaz, pero la época del cacicazgo como hacienda vinculada había pasado, y afrontó la tarea de cortar por lo sano. Hubo largos y caros conflictos con Zapotitlán Palmas, y Andrés decidió vender sus propiedades en Cuyotepeji a los inquilinos anteriores del pueblo sólo para eximirse de los pleitos (Monaghan 2005: 420). Cuando Andrés murió en 1881, las propiedades se dividieron entre sus seis hijos. Reservaron unas tierras para ellos mismos, vendieron otras a pueblos locales, y aún otras a parientes. La familia Villagómez fue prolífica a finales del siglo XIX y en los primeros años del siglo XX y las propiedades se dividieron más y más a través de los años. Las propiedades de los bisnietos de 
Andrés se medían en cientos de hectáreas en comparación con sus decenas de miles, y para los primeros años del siglo XX, los descendientes Villagómez poseían sólo terrenos pequeños que apenas se distinguían de las parcelas de los descendientes de los antiguos terrazgueros del cacicazgo (Monaghan 2002: 3; Monaghan et al. 2003: 133).

En la época de la reforma agraria de los 1930s después de la Revolución, una cantidad considerable de antiguas tierras de cacicazgo estaba en manos de pueblos mixtecos, o como ejidos o como propiedad privada de asociaciones locales llamadas «sociedades agrícolas». Los descendientes Villagómez en Suchitepec controlaban todavía 5.000 hectáreas en 1936, y aunque el cacicazgo había dejado de existir hacía mucho tiempo, sigue viviendo en la memoria hasta hoy. Se dice que la antigua familia de Villagómez tenía la única casa de dos pisos en el pueblo. Según algunos informantes, antes de la reforma agraria de los 1930s, vecinos en Suchitepec todavía pagaban renta a los Villagómez para pastorear sus animales y para la caza y la recolección de leña y fruta (Steffan Riedemann 2001: 64, 191).

\section{Conclusión}

El cacicazgo Villagómez de Suchitepec fue excepcional en la Mixteca por su tamaño, su persistencia en los siglos XVIII y XIX, y su falta aparente de una base prehispánica. Pero en su estructura básica y su forma de crecer, tenía mucho en común con otros cacicazgos de la región. Este caso subraya de nuevo la importancia de los lazos matrimoniales entre familias cacicales en la formación y crecimiento de las haciendas indígenas, un patrón antiguo en la Mixteca. El caso de los Villagómez también demuestra cómo herederos de los cacicazgos más grandes se fueron enajenando cada vez más, culturalmente y a veces físicamente, de sus comunidades y de su gente. Mantener su status como cacique frecuentemente requería alinearse con el mundo español criollo, y hacia el fin de la colonia los matrimonios entre caciques y criollos eran bastante comunes (Chance 2008, 2009; Monaghan 2006; Pastor 1987: 168-169). Para muchos caciques, incluso los Villagómez, sus tratos con arrendatarios y comerciantes españoles tenían la misma importancia que sus relaciones con sus terrazgueros mixtecos. Estas consideraciones sociales y económicas, junto con los conflictos endémicos con los pueblos sobre propiedad de tierras, ayudan a explicar la desaparición gradual de los caciques de los cargos políticos formales en sus comunidades, especialmente el de gobernador. A este respecto, la Mixteca Baja no era diferente de otras partes del México colonial. González Hermosillo señala que a principios del siglo XVIII, los herederos dinásticos de la mayoría de las provincias de Nueva España ya no servían como gobernadores. El interés de los caciques en los cargos municipales disminuía a lo largo del siglo, y algunos nobles veían servicio en tales cargos como indigno de ellos (González Hermosillo 1998: 67) ${ }^{10}$.

10 Hubo excepciones notables. Por ejemplo, en Tepexi de la Seda, un pueblo de lengua popoloca y nahua al norte de la Mixteca, las cinco familias de caciques dominaron el cargo de gobernador durante el siglo XVIII (Cruz Pazos 2008; Menegus Borneman 2008: 101,130-133). 
La historia del cacicazgo Villagómez sugiere que los investigadores han subestimado la importancia del faccionalismo y la diversidad de puntos de vista en los pueblos indígenas. La mayoría de la información que nos proporcionan los archivos sobre la política interna de los pueblos mixtecos se filtra por las repúblicas, que a veces representaban consensos locales, pero frecuentemente no lo hicieron. En efecto, las muchas instancias de conflicto en los pueblos del cacicazgo Villagómez demuestran que en muchas comunidades no hubo consenso. En el caso de Cuyotepeji mencionado arriba, aún mientras las relaciones entre cacique y algunos vecinos eran distantes y hostiles, el reconocimiento de derechos señoriales por otros y el pago de terrazgo, aún si era principalmente simbólico, continuaba. Éste no fue un caso aislado, y la continuidad subyacente del pago de terrazgo se vio oscurecida muchas veces por los conflictos crecientes entre los caciques y las repúblicas (Chance 2010). Estos conflictos eran bastante reales, pero la variedad de opiniones hacia los caciques en los pueblos fue más grande de lo que a menudo reconocemos. Así no debe sorprendernos que las antiguas formas ideológicas de sostener el status de cacique persistieran en la Mixteca Baja hasta principios del siglo XX, o que las historias orales aún hoy se refieran a caciques como yya, el término mixteco antiguo para élite (Monaghan 1997: 271). Que el cambio político no excluía una significativa continuidad cultural, lo subraya el hecho de que los cacicazgos permanecieron siendo instituciones híbridas hasta mediados del siglo XIX, combinando, con inquietud, nociones indígenas del privilegio noble con conceptos europeos de la propiedad privada.

\section{Referencias documentales}

BN (Biblioteca Nacional de México, México, D.F.). Sección Tenencia de la Tierra en Puebla.

AGI (Archivo General de Indias, Sevilla). Sección Audiencia de México.

AGN (Archivo General de la Nación, México, D.F.).

Ramos de Indios y Tierras

AGNP (Archivo General de Notarías del Estado de Puebla, Puebla).

Protocolos de Acatlan.

AHJO (Archivo Histórico Judicial de Oaxaca, Oaxaca)

Sección de Huajuapan, Ramo Civil.

\section{Referencias bibliográficas}

CAso, Alfonso

1958 «El Mapa de Xochitepec», en Proceedings of the 32nd Internacional Congress of Americanists, pp. 458-466. Copenhagen: Internacional Congress of Americanists. 
Cruz Pazos, Patricia

2008 «Juan de Moctezuma y Cortés: el ascenso al poder de un cacique indígena (Tepexi de la Seda, 1703-1778)». Revista Española de Antropología Americana 38 (1): 31-50.

Chance, John K.

1998 «La hacienda de los Santiago en Tecali, Puebla: un cacicazgo nahua colonial, 1520-1750». Historia Mexicana 47 (4): 689-734.

2003 «Haciendas, Ranchos, and Indian Towns: A Case from the Late Colonial Valley of Puebla». Ethnohistory 50 (1): 15-45.

2008 «Alianzas matrimoniales coloniales entre caciques mixtecos: El caso de AcatlanPetlalcingo». Anuario de Estudios Americanos 65 (1): 71-86.

2009 «Marriage Alliances among Colonial Mixtec Elites: The Villagómez Caciques of Acatlan-Petlalcingo». Ethnohistory 56 (1):91-123. doi: 10.1215/00141801-2008037; http://dx.doi.org/10.1215/00141801-2008-037

2010 «From Lord to Landowner: The Predicament of the Late Colonial Mixtec Cacique». Ethnohistory 57 (3): 445-466. doi: 10.1215/00141801-2010-005; http:// dx.doi.org/ 10.1215/00141801-2010-005

GonzÁlez Hermosillo, Francisco

1998 «La élite indígena de Cholula en el siglo XVIII: el caso de don Juan de León y Mendoza», en Círculos del poder en la Nueva España, Carmen Castañeda, coord., pp. 59-103. México: CIESAS.

Menegus Borneman, Margarita

2008 «La territorialidad de los cacicazgos y los conflictos con terrazgueros y los pueblos vecinos en el siglo XVIII», en Prácticas populares, cultura política y poder en México, siglo XIX, Brian F. Connaughton, coord., pp. 97-139. México: Casa Juan Pablos, Universidad Autónoma Metropolitana.

2009 La Mixteca Baja entre la Revolución y la Reforma: Cacicazgo, territorialidad y gobierno siglos XVIII-XIX. Oaxaca: UABJO, UAM-H y Congreso del Estado de Oaxaca.

Monaghan, John

1997 «Mixtec Caciques in the Nineteenth and Twentieth Centurias», en Codices, caciques y comunidades, Maarten Jansen y Luis Reyes García, coords., pp. 265-281. Cuadernos de Historia Latinoamericana, 5. Leiden: Asociación de Historiadores Latinoamericanistas Europeos.

2002 «The Indigenous Nobility and the Reinscription of Mesoamerican Codices: Preliminary Findings». Foundation for the Advancement of Mesoamerican Studies. Documento electrónico, <http//www.famsi.org/reports/99031es/section03.htm>, con acceso el 14/2/2011.

2005 «Mixtec Codices and the Transition from Noble Estates to Corporate Communities in the Nineteenth Century», en Painted Books and Indigenous Knowledge in Mesoamerica: Manuscript Studies in Honor of Mary Elizabeth Smith, Elizabeth Hill Boone, ed., pp. 415-426. Nueva Orleans: Middle American Research Institute, Tulane University.

2006 «Mixtec Cacique Marriages». Ponencia presentada en el Annual Meeting of the American Society for Ethnohistory, Williamsburg, VA, 4 de noviembre. 
Monaghan, John, Arthur Joyce y Ronald Spores

2003 "Transformation of the Indigenous Cacicazgo in the Nineteenth Century». Ethnohistory 50 (1): 131-150. doi: 10.1215/00141801-50-1-131; http://dx.doi.org/ 10.1215/00141801-50-1-131

PASTOR, Rodolfo

1987 Campesinos y reformas: La Mixteca, 1700-1856. México: El Colegio de México.

Romero, $\mathrm{M}^{\mathrm{a}}$ de los Angeles y Ronald Spores (comps.)

1976 Índice del Archivo del Juzgado de Teposcolula, Oaxaca: Época Colonial. Cuadernos de los Centros, 32. México: INAH.

Sмiтh, Mary Elizabeth

1998 The Codex López Ruiz: A Lost Mixtec Pictorial Manuscript. Vanderbilt Publications in Anthropology, 51. Nashville: Vanderbilt University.

Steffan Riedemann, Cristina

2001 Los comerciantes de Huajuapan de León, Oaxaca, 1920-1980. México: Universidad Autónoma Metropolitana y Plaza y Valdés.

TERRACIANO, Kevin

2001 The Mixtecs of Colonial Oaxaca. Stanford: Stanford University Press. 